\title{
E-gov Transparency Implementation Using Multi-agent System: a Brazilian Study-Case in Lawsuit Distribution Process
}

\author{
Denis José Albuquerque ${ }^{1}$, Vanessa T. Nunes ${ }^{1}$, Célia G. Ralha ${ }^{1}$, Claudia Cappelli ${ }^{2}$ \\ ${ }^{1}$ Departamento de Ciência da Computação - Universidade de Brasília (UnB) \\ Caixa Postal 4466 - Brasília - DF - 70.904-970 \\ denisalbuquerque@gmail.com,vanunes@gmail.com,ghedini@unb.br \\ ${ }^{2}$ Programa de Pós-Graduação em Informática - Universidade Federal do Estado do Rio de \\ Janeiro (UNIRIO) - Av. Pasteur, 458, Urca - Rio de Janeiro - RJ - 22.290-240 \\ claudia.cappelli@uniriotec.br
}

\begin{abstract}
Electronic government (e-gov) processes need transparency in order to allow citizens to access, understand and verify valuable information in a democratic society. As a crosscutting characteristic, transparency should be present in different e-gov perspectives, such as business processes, information, business rules and information systems. Thus, in this article, we present a multi-agent system (MAS) to implement transparent lawsuit distribution process. We demonstrate that the MAS paradigm emphasizes the organizational operating environment and the information systems alignment, being adequate to implement process transparency under a Brazilian study-case in lawsuit distribution that used real data from the Superior Labor Court of Brazil. The Tropos agent-oriented software development methodology is used to define the hard and soft goals of agents. The $M A S$ architecture and the prototype were defined and implemented using JADE Framework.
\end{abstract}

\section{Introduction}

According to the United Nations Public Administration Country Studies (UNPACS) ${ }^{1}$, the concept of e-gov has been employed to express the use, by the government, of Information and Communication Technologies (ICT) in the provision of public services to the population, companies and other government areas. An underlying principle of e-gov is to improve the internal functioning of the public sector, reducing financial costs and transaction times. Thus, it is possible to better integrate processes and services, besides allowing the use of effectively resources in various public sectors, providing sustainable solutions.

${ }^{1}$ http://unpan3.un.org/egovkb/en-us/
In fact, society has increasingly demanding access to information by digital means. In Brazil, the Federal Government published in 2015 the Brazilian Strategy of Digital Governance (Estratégia de Governança Digital - EGD) ${ }^{2}$ aiming to guide and integrate the initiatives related to digital governance in the Federal Government. It contributes to increase effectiveness in the generation of benefits for the society by expanding access to government information, improving digital services and increasing social participation.

One of the principles that EGD lists is related to openness and transparency. It states that, accordingly to the Brazilian Access to Information Law (Law ${ }^{\circ}$ 12.527, 2011) and Transparency Law (Law $\mathrm{n}^{\mathbf{0}} 131$, 2009), data and information are public assets that should be available to society in order to promote transparency and publicity to the use of public resources in programs and services, generating social and economic benefits.

This principle converges with the fact that the opening of the flow of information through ICT is creating an open society. This openness aims to establish democracy among citizens engaged with the ability to understand and access information and knowledge [9]

Another vital aspect of a democratic society is related to combating corruption. According to the last annual assessment of the Transparency International Organization $^{3}$ corruption remains a "plague" in the world. The year of 2015 served to make clear that society no longer tolerates these actions and demands that this problem must be faced by all countries. Brazil does not show up well in this scenario getting 38 points (from 0 - highly corrupt 100 - clean). This score has

\footnotetext{
${ }^{2}$ See the EGD proposition at:

http://www.sisp.gov.br/egd/wiki/download/file/Minuta_EGD

${ }^{3}$ https://www.transparency.org
} 
been falling since 2012, but in 2015 Brazil was the country that had the largest decline in this fight getting the 76th place of 168 countries assessed. For this reason, transparency, or lack thereof, has been at the top of the Brazilian public agenda in many aspects and its importance has been highlighted by the increasing demand for the provision of e-gov. In this sense, the application of transparency characteristics, is a new and important concern when designing software that automates the delivery of services, processes information and interacts with people [14]. Accordingly to the authors in [6], transparency in Brazilian e-gov (a.k.a. e-transparency) is also a subject still in the beginning of its maturing process.

Thus, our research group focuses on the transparency implementation in e-gov, taken as a research working scenario the Brazilian Judicial Process System. According to the Brazilian National Council of Justice (Conselho Nacional de Justiça CNJ), only in 2014, more than 28 million lawsuits ${ }^{4}$ were started and around 5 million $^{5}$ were entirely processed by the Brazilian Electronic Judicial Process System (Sistema de Processo Judicial Eletrônico PJe). In 2015 this number increased to 5,274 million and growth is progressing. Nevertheless, the use of electronic lawsuit distribution is still heavily criticized because of the lack of transparency. The main problem it causes is related to fraud in the distribution process in order to bias the sortation process. ${ }^{6789}$ Since society cannot have access and visualize how a lawsuit distribution occurred people are not aware of why a lawsuit was designed to a judge. Periodic inspections ${ }^{10}$ and complaints are not effective and most of the times occur after lawsuits are judged.

In this regard, this paper proposes the design and implementation of a multi-agent system (MAS) that implement transparency characteristics under the process of lawsuits distribution. The design and implementation of e-gov is considered one of the main research themes cited by [19] in their literature review on researches on e-gov in Developing Countries. However, the e-gov transparency design and

\footnotetext{
${ }^{4}$ http://www.cnj.jus.br/files/conteudo/arquivo/2015/11/491328c3314 4833370f375278683f955.pdf

5 http://www.cnj.jus.br/noticias/cnj/80258-pje-supera-marca-dos-5milhoes-de-processos-eletronicos?acm=264425_7457

${ }^{6}$ http://www.conjur.com.br/2014-fev-12/cnj-demite-servidores-tjma-fraude-distribuicao-processos

${ }^{7}$ http://www.conjur.com.br/2014-out-25/entravista-damares-medinacoelho-advogada-pesquisadora

${ }^{8}$ http://www2.ana.gov.br/Paginas/imprensa/noticia.aspx ?List=ccb75a 86-bd5a-4853-8c76-cc46b7dc89a1\&ID=11622

${ }^{9}$ http://www.conjur.com.br/2014-dez-10/chefe-procuradoriacriminal-sp-promete-transparencia 10http://www.trf1.jus.br/dspace/bitstream/handle/123/52798/INSPE\%C3\%87\%C3\% 830\%202015\%20-\%20EDITAL.pdf?sequence $=1$
}

implementation was not a subject of research discussed in the set of reviewed papers.

A first discussion and prototype over this theme was presented by Albuquerque et. al [1]. We argue that MAS provide an interesting way to simulate societies, which may help to shed some light on various kinds of social processes [20]. MAS can represent real-world problems in its natural complexity, which cannot usually be solved by individual agents without have a cognition process. Although adding more complexity, MAS paradigm has features that favor the decomposition of problems or a complex work system into parts. These parts are represented by independent elements, with different characteristics, which can be modeled on an individual basis, where the understanding of each entity can only be done by the integrated set of parts, where the principle of interaction between entities in a dynamic, distributed and heterogeneous environment is essential.

The design of how agents interact with each other and with the environment is essential to understand and define the level of understandability, accessibility, clarity, integrity, auditability, and other transparency characteristics necessary when automating a business process related to a public service. The development of a MAS prototype clarified the understanding of how a traditional corporate information system may be developed from the agent paradigm.

In this work, we continue our investigation of the understandability aspects of transparency and we introduced the auditability characteristics proposed by Cappelli [4] in order to improve transparency over the lawsuits distribution Process. A study case using a Brazilian Judicial Process System scenario was developed in order to illustrate the presented MAS solution and to show the improvements in relation to the current lawsuit distribution system at the TST. We intended to investigate how transparency about the interaction among agents might help treat requirements related to understandability and auditability. Those were recognized as the main problems reported by users and it were possible to perceive advances considering these transparency issues.

The rest of the paper is structured as follows: Section 2 presents Transparency definition and the Transparency SIG (Softgoal Interdependency Graph) proposed by Leite and Cappelli [14]. SIG is being used as a conceptual model in this research, including the understandability and auditability characteristics. Section 3 discusses the Lawsuit Process Flow under the current e-gov and presents the problems resulting from the lack of transparency in the lawsuit distribution process. Section 4 presents the architectural solution and the implemented prototype. Section 5 presents the results from a Study Case using 
real data and Section 6 concludes the paper presenting future research initiatives.

\section{Transparency}

The demand for transparency has been in the agenda of public organizations. Different authors provide different definitions for transparency. Holzner and Holzner [11] state that transparency is "The social value of open, public, and/or individual access to information held and disclosed by centers of authority". Lord [15] says: "Transparency is a condition in which information about the priorities, capabilities, and behavior of powerful organizations is widely available to the global public". Fung et al [9] use the concept of target transparency: "Instead of aiming to generally improve public deliberation and officials' accountability, target transparency aims to reduce specific risks or performance problems through selective disclosure by corporations and other organizations. The ingeniousness of target transparency lies in its mobilization of individual choice, market forces, and participatory democracy through relatively light-handed government action". In the public context [10], it is believed that access to information creates a democratic society with participating citizens that are able to understand and use the information that is accessible to them.

In order to make concrete such abstract concept, in this paper we are going to use the definition proposed by Leite and Cappelli [14]. Their concern was, fundamentally, on how to implement transparency in organizations through software and they defined the concept of organizational transparency as being a set of aspects that suggest the existence of policies which allow stakeholders to provide information according to the following general characteristics: access, use, presentation, understanding and auditability as presented in Figure 1.

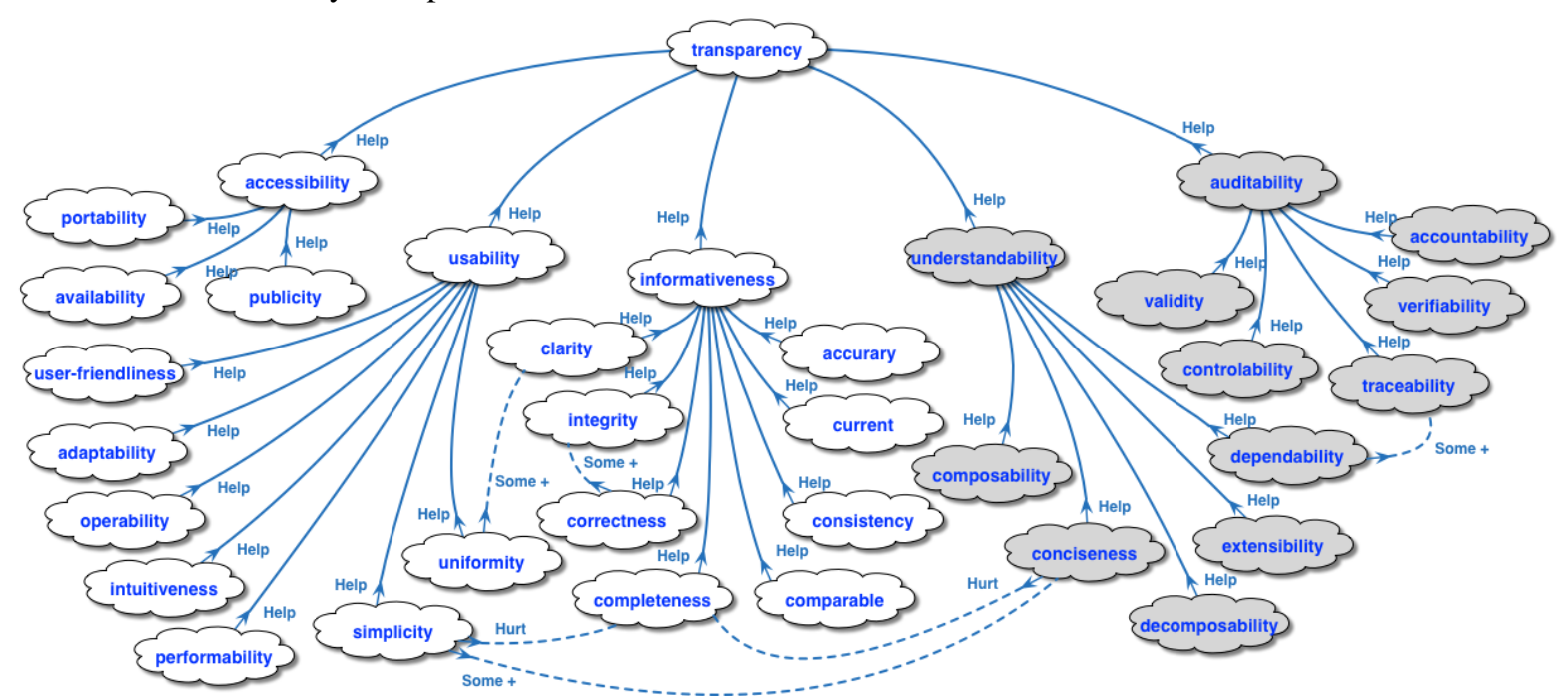

Figure 1 - Transparency SIG (Softgoal Interdependency Graph) [14]

For each characteristic, a set of operationalization and mechanisms was proposed in order to orient the introduction of transparency aspects in organizational processes. Table 1 presents the characteristic that helps to satisfy the Auditability Group that represents the ability to examine carefully for accuracy with the intent of verification. The understandability characteristics are described in [1].

However, the implementation of the concept of transparency is difficult to achieve in organizations. In practice, what is observed is the attempt of applying it at a limited extent, trying to follow the practices (related to a subset of the characteristics proposed in [14]) that the regulatory instruments demand. In IS area, some researches have been trying to better understand how transparency will be operationalized in the process of systems construction [12][14]. In the case of business processes, Cappelli [4] has proposed a series of operationalization to introduce the transparency quality in the process models. In this research we focused transparency by modeling its requirements as a softgoal graph, as proposed by the NFR (Non-Functional Requirements Framework [8]).

Note that if process and service are to consider transparency, their operationalization will have to be dealt with in the supporting software as well.

\section{Lawsuit Process Flow}

The Superior Labor Court (Tribunal Superior do Trabalho - TST) of the Brazilian Judiciary branch is a specialized court responsible to judge lawsuits arising 
from conflicts on labor relations and represents the third instance of jurisdiction on labor courts' organization. Above the TST only the Federal Supreme Court (Supremo Tribunal Federal - STF) has a final and incontestable decision, when prompted to deal with constitutional matters.

Table 1 - The auditability characteristics [4]

\begin{tabular}{|c|c|}
\hline Characteristic & Validity \\
\hline Definition & The ability of being valid and rigorous \\
\hline $\begin{array}{l}\text { Operationaliza } \\
\text { tion impact }\end{array}$ & $\begin{array}{l}\text { - Relate processes x goals } \\
\text { - Test processes } \\
\text { - Relate activities goals x generated } \\
\text { products } \\
\text { - Simulate processes } \\
\text { - Identify information sources }\end{array}$ \\
\hline Characteristic & Controllability \\
\hline Definition & The ability of being certain of something \\
\hline $\begin{array}{l}\text { Operationaliza } \\
\text { tion impact }\end{array}$ & $\begin{array}{l}\text { - Calculate estimated x realized } \\
\text { - Perform simulation } \\
\text { - Register start and end of activities } \\
\text { - Register participating actors } \\
\text { - Register decisions taken } \\
\text { - Define process control points } \\
\text { - Check information } \\
\text { - Register used resources }\end{array}$ \\
\hline Characteristic & Traceability \\
\hline Definition & $\begin{array}{l}\text { The ability of following, discover, or } \\
\text { ascertain the course of development of } \\
\text { something }\end{array}$ \\
\hline $\begin{array}{l}\text { Operationaliza } \\
\text { tion impact }\end{array}$ & $\begin{array}{l}\text { - Identify software requirements } \mathrm{x} \\
\text { activities } \\
\text { - Identify the context of changes } \\
\text { - Identify when changes are made } \\
\text { - Identify the location of change } \\
\text { - Identify information x processes } \\
\text { instances } \\
\text { - Identify changes reasons } \\
\text { - Identify responsible for changes } \\
\text { - Identify predecessors activities } \\
\text { - Identify successors activities } \\
\text { - Identify the processes changes } \\
\text { - Identify dependencies among processes }\end{array}$ \\
\hline Characteristic & Verifiability \\
\hline Definition & $\begin{array}{l}\text { The ability of being tested (verified or } \\
\text { falsified) by experiment or observation }\end{array}$ \\
\hline $\begin{array}{l}\text { Operationaliza } \\
\text { tion impact }\end{array}$ & $\begin{array}{l}\text { - Relate goals x processes } \\
\text { - Connect inputs, outputs and activities } \\
\text { - Relate events and processes } \\
\text { - Linking actors and activities } \\
\text { - Relate information x processes } \\
\text { instances } \\
\text { - Relate processes and activities } \\
\text { - Relate software requirements x } \\
\text { activities } \\
\text { - Relate organizational structure and }\end{array}$ \\
\hline
\end{tabular}

\begin{tabular}{|c|c|}
\hline & $\begin{array}{l}\text { activities } \\
\text { - Provide descriptions of activities }\end{array}$ \\
\hline Characteristic & Accountability \\
\hline Definition & $\begin{array}{l}\text { The quality of being explained; made } \\
\text { something plain or intelligible }\end{array}$ \\
\hline $\begin{array}{l}\text { Operationaliza } \\
\text { tion impact }\end{array}$ & $\begin{array}{l}\text { - Identify how goals are achieved } \\
\text { - Identify why events trigger processes } \\
\text { - Identify how events finalize processes } \\
\text { - Justify the need of entries } \\
\text { - Justify existing decisions in the flow } \\
\text { - Justify the generated output } \\
\text { - Justify the sequence of activities } \\
\text { - Identifying information x processes } \\
\text { instances } \\
\text { - Identify software requirements x } \\
\text { activities } \\
\text { - Justify the } \\
\text { organizational structure } \\
\text { - Identify the definition of the } \\
\text { information content } \\
\text { - Justify the existence of every activity } \\
\text { - Justify the need for each actor }\end{array}$ \\
\hline
\end{tabular}

A process starts at TST when: an appeal is made to contest a lower instance decision; or with the delivery of an initial petition in specific cases, which can be made in person presenting the document at TST's protocol department or virtually using the Integrated System for Electronic Document Protocol and Flow (Sistema Integrado de Protocolização e Fluxo de Documentos Eletrônicos - eDOC). Thenceforth, a simplified TST Lawsuit process flow is depicted in Figure 2.

The lawsuit distribution is the act that defines the judging magistrate responsible for leading and judging a particular court case. It is considered one of the main activities in order to provide a fair judging process, which can help to guarantee impartiality of decisions, while seeking to preserve the natural justice principle ${ }^{11}$. It is observed under the Law 13,105 of March 16, 2015 (Civil Process Code - CPC) $^{12}$ that establishes rules for the lawsuit distribution that befits the principles of legality, impersonality, morality, publicity and efficiency (Article 37 of the Brazilian Federal Constitution $^{13}$ ).

Nevertheless, the $\mathrm{CNJ}^{14}$ states that "It is not uncommon to note, in the actual distribution system, failures that enhance the emergence of deviations, either by intention or negligence". Problems like, the

\footnotetext{
${ }^{11}$ https://www.ombo.nsw.gov.au/_data/assets/pdf_file/0017/3707/F

S_PSA_14_Natural_justice_Procedural_fairness.pdf

${ }_{12}$ http://www.planalto.gov.br/ccivil_03/_Ato20152018/2015/Lei/L13105.htm

${ }^{13} \mathrm{http} / / /$ www.planalto.gov.br/ccivil_03/Constituicao/Constituicao.ht $\mathrm{m}$

${ }^{14}$ http://www.cnj.jus.br/wikipje/index.php/
} 
lack of transparency on information handled, omission of information and unclear selection of criteria, make it is clear the problem of lack of transparency in the distribution process that may suggest little or no randomness in the distribution process and, inequity of the Justice Power.

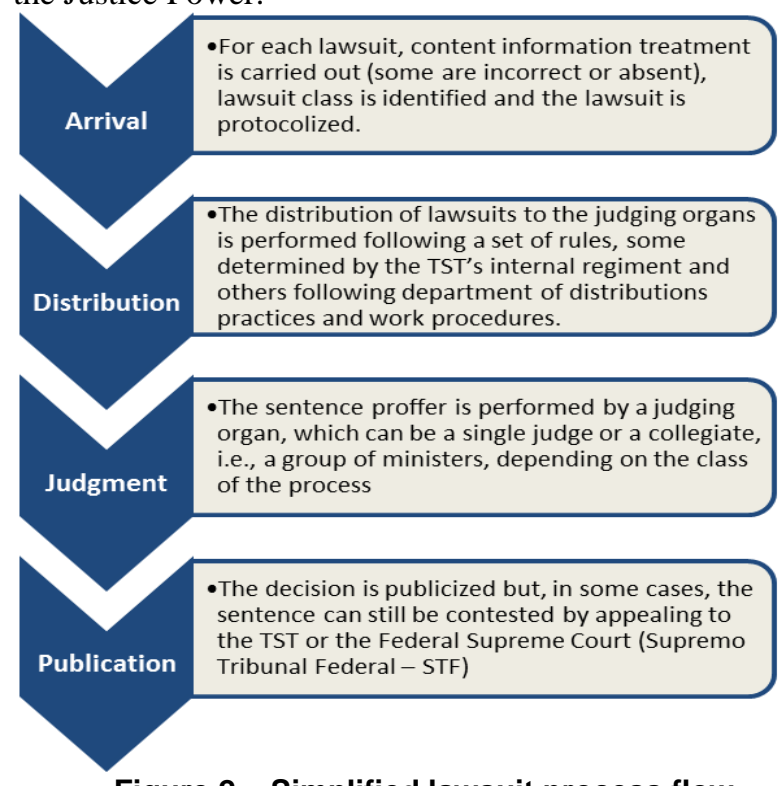

Figure 2 - Simplified lawsuit process flow

Especially considering the study-case at the TST, where the lawsuit distribution is performed by software, its functions and information are not disclosed to users, but only the final results of the distribution. In this case, if someone needs to audit or requires information about the reasons why a specific lawsuit $\mathrm{X}$ was distributed to Magistrate $\mathrm{Y}$, it is necessary to ask the IT staff so they can check into the database, what is time consuming and even not very explanatory. In 2015, TST distribution department held the distribution of 195,867 lawsuits ${ }^{15}$. Currently, the system performs electronic distribution using a random process attribution that considers the registered magistrates able to judge. The system also makes use of compensation rules promoting the distribution in equal loads (the number of cases handled by a judge or a court) by the judging magistrates and processual classes, taking into account distributions previously taken, reallocations and their cancellations.

\section{The implemented Multi-agent System}

Research on technologies applied on e-gov has increased in recent years, focusing on various fields of research, such as software engineering, knowledge

\footnotetext{
${ }^{15}$ http://www.tst.jus.br/documents/10157/350f2e53-bb87-4df0-9a90126e6be1a85d
}

engineering, interoperability at all levels (including semantics) and business processes [16][18]. Most researches cite the importance of promoting transparency as one of its main goals, but as far as we are aware there are no approaches that address transparency issues systematically.

In this sense, the application of transparency to egov is a new and important concern when designing IS that gives public information to citizens. Transparency is a crosscutting concern and it can be designed using aspect-oriented paradigm, which can be implemented through an agent. The aspect-oriented paradigm [13] proposes the modularization of crosscutting concerns used in programming area. Cappelli [4] brought it to business process level and consequently to IS level, while Leite and Cappelli [14] detailed them into softgoals to be implemented in software.

Thus, this paper presents the implementation of transparency in software through the use of MAS paradigm, illustrated by the problem of lawsuit distribution. The current MAS prototype version was developed using the JADE framework, which is a middleware for the development of agents that support FIPA $^{16}$ specifications [2].

In [5], authors establish various properties of agents that need to be considered in order to build agentoriented software: autonomy, deliberativeness, reactivity, organization, socialization and interaction. They also state that agents must have planning mechanisms to perform their actions and be flexible to changes in the environment.

In literature, the MAS paradigm is recognized to be suitable for the development of complex systems, since agents can represent a natural abstraction to decompose entities in systems [5][20]. Thus, agents have specific roles, goals, tasks and resources, all conceived in relation to a collection of modules, data structures and interfaces that interact with the environment.

Considering agents' interactions, the MAS design is very important to understand and define the level of collaboration, negotiation, clarity, integrity, accountability, traceability, and other transparency characteristics related to the automation of business process for public services.

While MAS design, we studied the problem by comprehending the organizational context [3]. It was used Tropos, an agent-oriented software engineering (AOSE) methodology, which is driven by requirements and seeks to support different phases of agent-based systems development. This methodology has five steps (early requirements, late requirements, the architectural

\footnotetext{
${ }^{16}$ FIPA (The Foundation for Intelligent Physical Agents) is an IEEE organization that promotes standardization of technologies related to agents and their interoperability.
} 
specification, detailed project and the implementation) and adopts the framework I* (ISTAR - Intentional Strategic Actor Relationships modeling) that employs concepts such as actors, agents, positions, roles, social dependencies, goals, tasks and resources [21].

Figure 3 shows the late requirements model. Note that there are three different agent types. The Protocol Agents (PAs), that identify, in the Electronic Judicial Processes Database, the lawsuits ready for distribution and associated information required to carry out this activity. They must have the intelligence to identify, for example, related lawsuits in order to distribute them to the same judging magistrate. Information obtained by the PAs is transmitted to Distribution Agents (DAs) when requested. The PAs also update lawsuits database with information about the progress of their processing from information received from the DAs.

The Magistrate Agents (MAs) obtain information about a magistrate, such as impediments and personal information. MAs can have the intelligence to automatically find new impediments and suspicions regarding a magistrate even though the respective one does not provide them. As an example, a MA could find out that a magistrate is related to one of the parties involved in a lawsuit.

The DAs receives lawsuits from the PAs and apply distribution rules considering also the information received from the MAs.

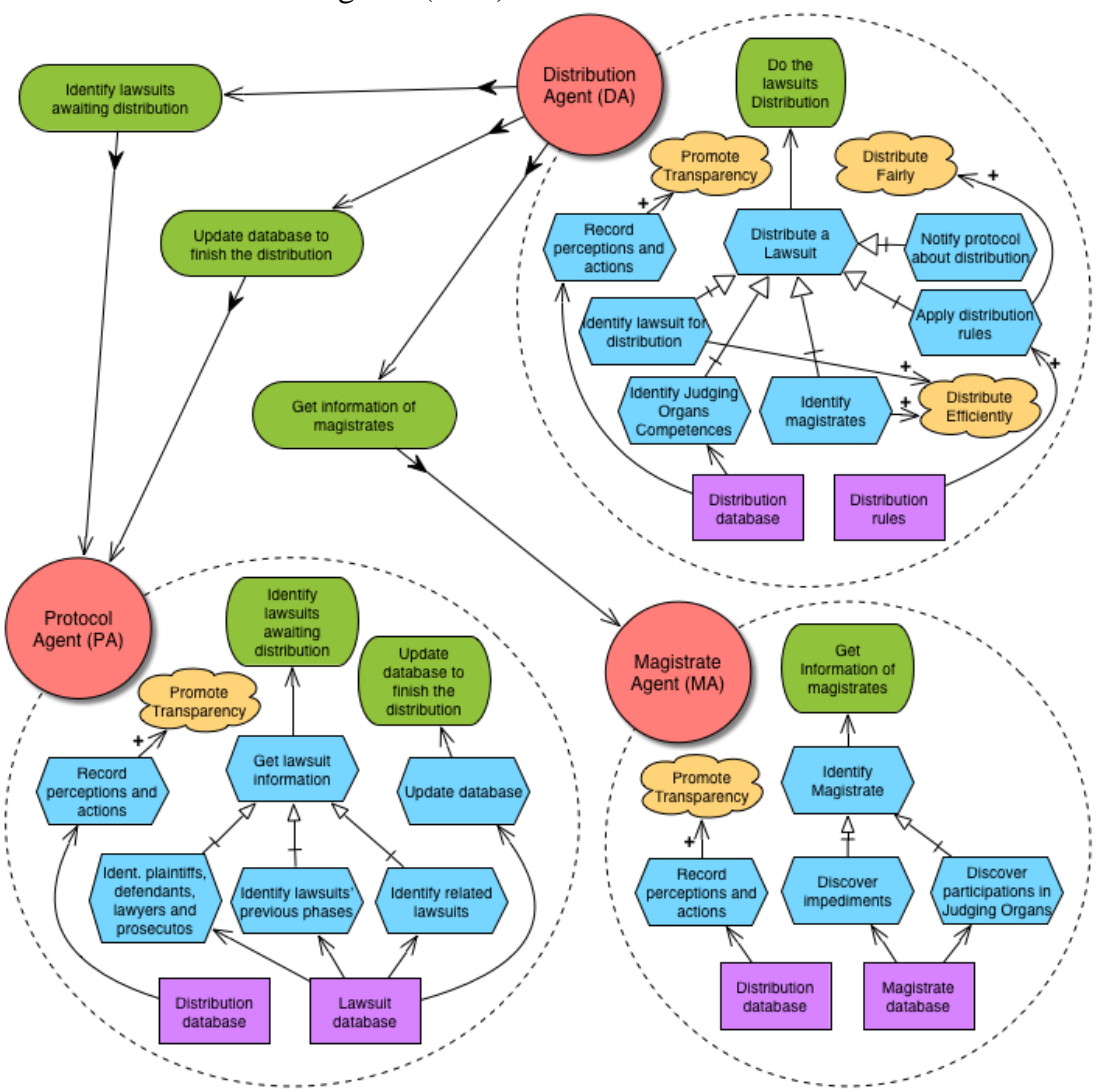

Figure 3 - Late requirements for the Lawsuits Distribution

Figure 4 presents the proposed Lawsuits Distribution Architecture. It shows the interrelations with the existing applications that already support the TST's Electronic Judicial Process as follows:

- The Judicial IS handles the process content and its movement among the various departments that operate the process since its assessment to the trial and the decision publication;

- There are other IS, such as eRemessa and eDoc, that addresses input / output of lawsuits and documents. Note that the process may come from lower instances (regional courts) or sourced from the TST. The output may return to lower courts or go to higher courts;

- There are IS that make use of lawsuits data for statistical matters of management information reports to support decisions;

Information from electronic processes is stored in centrally massive databases. Nowadays, many procedures and functions that implement business rules are contained in the Lawsuits database management systems (in stored procedures).

The architecture presented in Figure 4 is composed of the following components: 
- The Multi-Agent Platform Management is composed of three agents: (1) the Platform Manager Agent (PMA) responsible to start the MAS Application. It is responsible for loading as many as required PAs, DAs and MAs on the platform. To carry out its activities, the PMA recover the Judging Magistrates from the database;
(2) The Agent Management System (AMS) controls the platform, dealing with the creation, completion and other stages of the agents' life cycle; and (3) The Directory Facilitator (DF) provides a directory service for disclosure of which agents and services are available on the platform. All agents are registered in the DF to enable their discovery by other agents;

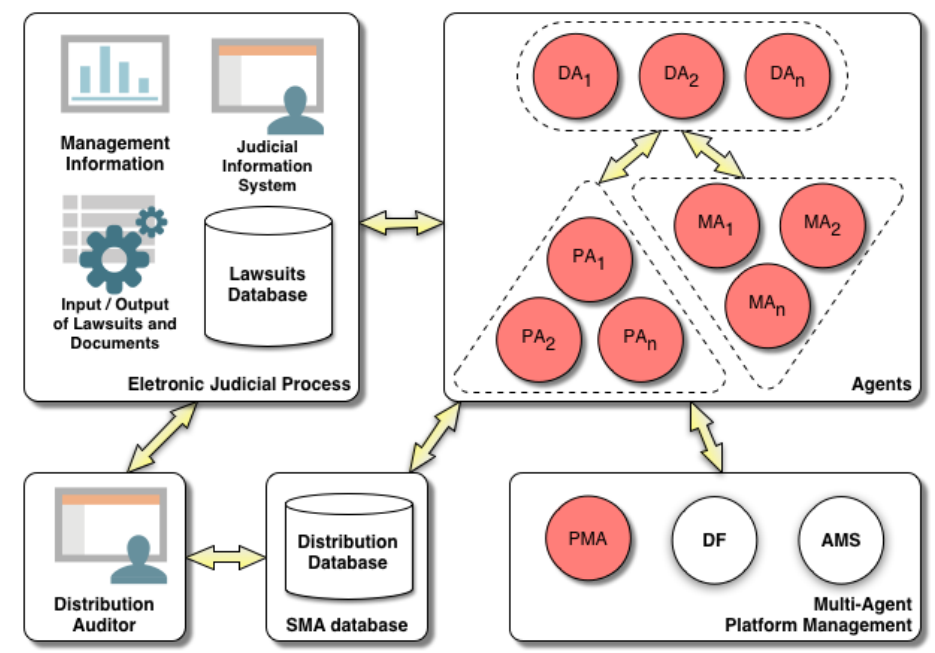

Figure 4 - Lawsuits Distribution Architecture

- The Information about Judging Magistrates is maintained in the Lawsuits database. MAs maintain this information in order to inform about impediments, suspicious, magistrate caseloads and any other information concerned to them;

- $\quad$ There are several PAs (PA1, PA2, ..., PAn), and each one is specialized in treating lawsuits from each Regional Courts, e.g., PA TRT1 interfaces with Regional Court of Rio de Janeiro to obtain the lawsuits from this region. PAs send lawsuits to DAs when requested, but PAs may also request DAs to initialize the processes distribution; There are several MAs (MA1, MA2, MA3, ..., MAn), each one representing one magistrate in the court. MAs may have intelligence to autonomously identify new impediments and/or suspicious information from other sources of information. They also register distribution information in a database including their actions and perceptions;

- $\quad$ There may be several DAs (DA1, DA2, .., DAn) for the purpose of distributing evenly the processing load or when each one is to use specific distribution rules for each lawsuit class. As an example, DA HC handles habeas corpus lawsuits and DA WM handles Writ of Mandamus. The distribution process can occur automatically, with the DAs performing their tasks on a scheduled basis, in an automated mode from the receipt of PA requests or by direct interaction with users. In order to provide traceability of decisions, DAs record the reasons why a particular case was assigned to a specific MA. The distributions rules are stored in the Lawsuits Database that is used by the DAs to run de lawsuits distribution.

- The Distribution Auditor is responsible to promote transparency of the information stored in the Distribution Database. Through it the interested parties may audit each one of the produced information.

All related concepts the lawsuits distribution processes were defined so as to establish a common reference of their interrelations. A partial view of the conceptual diagram is represented in Figure 5. The English definitions used are in conformance with the definition stated by the US Court glossary ${ }^{17}$, which have the same representations in the Brazilian Court.

For each MA, PA and DA it was developed a GUI interface so as the platform manager can monitor and decide.

\footnotetext{
${ }^{17}$ http://www.uscourts.gov/glossary
} 


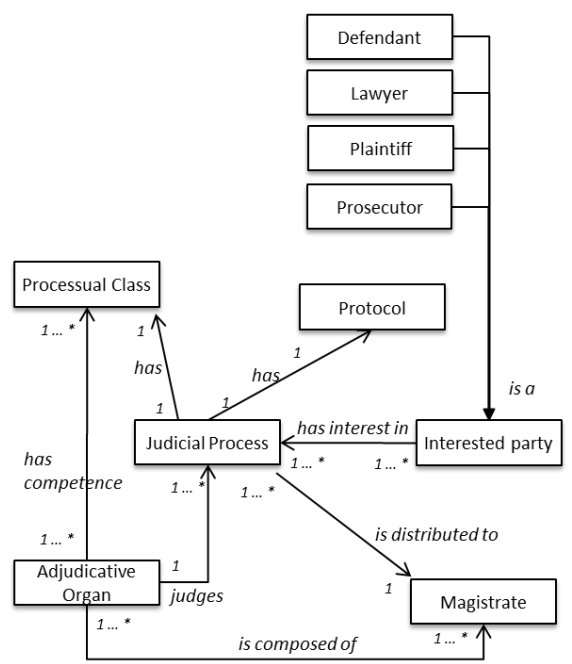

Figure 5-Part of the conceptual diagram.

\section{Brazilian Study Case}

The application that controls and executes lawsuits distribution resides almost entirely in procedures and functions stored in TST's database management systems. They were developed partly following rules defined by the Court's Internal Rules, but they were mostly built to meet existing working practices of the administrative departments that perform the activities of lawsuits assessment and distribution. There is no separation among rules and behaviors pertaining to each agent participating in the process which is confusing and causes a lack of transparency in the distribution process.

Besides, the current External Lawsuit Consultation website, as previously discussed in section 3, shows only to which Magistrate, the lawsuit is distributed to, as highlighted in arrows in Figure 6.

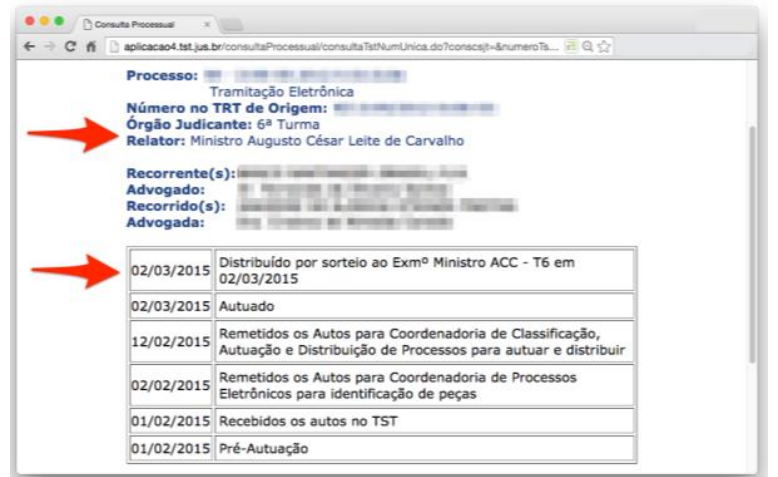

Figure 6 - TST Lawsuit Consultation System

It is not clear how legal and internal rules are taken into consideration in the process of lawsuits distribution. When a user requires explanation about the reason why lawsuit X was distributed to Minister
$\mathrm{Y}$, it is necessary to audit the database, what is time consuming and most of the time not explanatory.

Therefore, this study case was developed in order to analyze auditability and understandability transparency characteristics in relation to what is provided by the current lawsuit distribution application.

Based on the conceptual model presented in Figure 5, a database was implemented. The database was loaded with 309,332 lawsuits from previous years. There were 55 agents activated, as follows: (i) 25 PAs representing each one of the 24 Regional Labor Courts and the TST; (ii) 27 MAs representing each one of the TST Ministers; (iii) 1 centralized DA; (iv) 1 JADE DF; and (v) 1 JADE AMS.

Figure 7 presents a partial view of the Lawsuit Distribution Auditor that shows all details involving one specific distribution, to know: (i) Number of distribution (Número) and date (Data); (ii) Distribution rules applied (Regra); (iii) Distribution results (Resultado); (iv) Details of the random distribution considering competencies and impediments (Detalhes do sorteio); and (v) Details about the impediments of a specific Magistrate (Impedimentos para MMCP).

The distribution was even among the Magistrates and followed percentage rules specified previously (the Magistrates that are the TST president, vicepresident and Inspector General must receive less lawsuits than the others).

As transparency is a qualitative aspect (softgoal) and a transversal characteristic in the system, the evaluation was conducted empirically and through an intuitive analysis of the perception of the inclusion of transparency characteristics. For each of the Understandability and Auditability transparency characteristics

Table 2 and Table 3 discuss how they were attended.

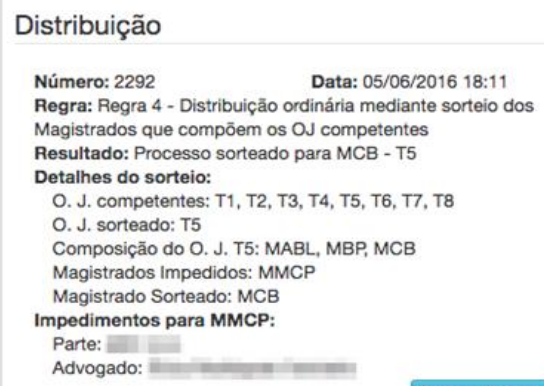

Figure 7 - TST Lawsuit Distribution Auditor Consultation System

Table 2 - The understandability implementation Understandability 
Conciseness

- Each agent represents a specific entity of the real world, with specific responsibilities and behaviors.

- The name of MA agents is composed of the initials of the magistrates' names.

- The name of PA agents is composed of the initials of the court that he works for.

- Each agent has a unique set of actions to perform and a set of information to treat.

Composability

- Each agent has a well-defined set of tasks to perform and the interfaces interactions.

- It is possible to compose each instance of the distribution process from the records of the agents' actions.

Decomposability

- Each agent decomposes distribution process into specific, independent and unique steps.

- Each agent is a specific real-world entity. The relationships between the agents were specified.

Extensibility

- It is possible to create new agents and introduce them into the system without interrupting ongoing procedures. The AGP agent is responsible for the agents' activation and deactivation.

- The introduction of new distribution rules of any type can also be performed easily and without system recoding.

Dependability

- The activities are clearly defined in the behavior of the agents.

- The dependence between agents is identified according to the responsibility of each entity in the process.

Table 3 - The auditability implementation

\begin{tabular}{l}
\hline Auditability \\
\hline Validity \\
\hline - The system was tested by experimentation and \\
observation, identifying that the process was properly \\
applied. \\
Controllability \\
- The control of which agents are active and thus, \\
participate in the process, is carried out by AGP agent \\
interface. \\
- The information on which agents were active and \\
participated in the distributions are all registered in the \\
database, allowing to identify the beginning and end of \\
each activity, as all actions taken by the agents are also \\
registered. \\
\hline Traceability \\
- It is possible to track which agents were involved in \\
each distribution process, identifying how, why and \\
when each of them act. \\
\hline Verifiability \\
- It is possible to check the relevance of the system when \\
comparing the results with those found in the TST. \\
\hline Accountability \\
\hline Each performed distribution is explainable from the \\
\hline
\end{tabular}

information stored in the database. It is possible to explain when the distribution was made, what rule was applied, which judging organs and magistrates participated in the activity and which magistrates' impediments were considered.

The development of the prototype clarified the understanding of how a traditional corporate information system may be developed using the agent paradigm. The MAS paradigm has features that favor the decomposition of problems, even though it adds considerable complexity in software construction. Employing middleware, such as JADE, needs developers with this extra specific expertise, but makes it possible to treat such complex problems. Furthermore, the complexity can be compensated by the achieved flexibility, making the architecture a good candidate for large and distributed systems which is the case of TST and its regional representations around the country.

Another empirical evidence is the fact that not only the lawsuit distribution process enhanced its level of transparency, but also the MAS design itself through a set of requirements and design model that promotes knowledge about the agents and the interaction among them. It represents a future subject of investigation considering the research work in [17] where the authors proposed an approach to deploy the transparency characteristics to software and software development process.

Although TST scenario (as the third out of three Labor Court instances plus the STF) was used in the study case, the Regional Labors Courts in the states have, in general, even lower levels of transparency in justice processes. This is a reality already noticed by [7] while researching transparency in budget and financial information.

Public organizations are increasingly seeking ways to automate their processes and the services they deliver to citizens. Transparency seems to be one of the crucial factors for raising the efficiency of these offerings, providing levels of control and increase their performance, thus strengthening egovernment initiatives.

\section{Conclusions and Future Work}

This paper focused on lawsuit distribution process inside of TST. This is a very relevant theme in the Brazilian Government since the legislative and judicial federal government powers showed a delayed reaction, among all powers, to effectively start to implement freedom of information actions defined in Brazilian Transparency Law. Therefore, as discussed in Section 3, judicial processes, in general, still lacks transparency which prevents citizens to understand and audit government information and processes. 
Transparency and communication are becoming a competitive advantage because of its moral perspective and its effectiveness in providing the ways and meanings of how services are provided by the government. More than that, transparency should be understood in a broad sense, including active transparency, which is realized through the provision, by the government, of public information of general or collective interest in a spontaneously way. The outcome of this realization is the high investments that are being conducted by the Brazilian Government in the development of communication and information technologies.

In this context, this paper is part of the work from a research group in Brazil that aims to systematize the introduction of transparency characteristics into e-gov, which still represents an open topic of research. Although the focus of the study case was on the lawsuit distribution, we believe that the solution can be studied and applied in other e-gov that aims to distribute processes/projects or any document to people in compliance with laws and internal regulations.

In order to systematize the design of transparency requirements we seek to define each characteristic in a quantitative and formal way, establishing software functional requirements.

Aknowledgement The presentation of this work was funded by FAPDF under process $n$. 14078.54.4465.14092016

\section{References}

[1] Albuquerque, D.J., Nunes, V.T., Ralha, C.G., Cappelli, C., "Implementing E-government Processes Distribution with Transparency using Multi-Agent Systems", iSys: Revista Brasileira de Sistemas de Informação, v.9, 2016, pp. 118-138.

[2] Bellifemine, F., Poggi, A., Rimassa, G., "Jade - a fipa compliant agent framework", Proceedings of PAAM, v.99, London, 1999, pp. 97-108.

[3] Bresciani, P., Perini, A., Giorgini, P., Giunchiglia, F., and Mylopoulos, J., "Tropos: An agent-oriented software development methodology",Autonomous Agents and Multi-Agent Systems, v.8, i.3, 2004, pp. 203-236.

[4] Cappelli, C., "An approach for business processes transparency using aspects". PhD thesis, Departamento de Informática, PUC-Rio, (in Portuguese) (http://wwwdi.inf.puc-rio.br/ julio/cappelli-tese.pdf), 2009.

[5] Castro, J., Kolp, M., Mylopoulos, J., "Developing agent oriented information systems for the enterprise," in Enterprise Information Systems,. Springer, 2001, pp.7-20.

[6] Coelho, T.R., Przeybilovicz, E., Cunha, M.A., Souza, T.H., "Positioning Brazil in International eGov research: a proposal based from literature review", 49th Int. Conf. on Sys. Sciences, Koloa, HI, 2016, pp.2677-2686.

[7] Coelho, T.R, Anderson, T., Cunha, M.A., Antonio, M., "Uncovering governmental transparency in federative states: diverse government spheres, heterogeneous outcomes", Proc. of the 2016 49th Int. Conf. on Systems Sciences (HICSS), Koloa, HI, USA, 2016, pp. 2209-2818.

[8] Chung, L., Nixon, B., Yu, E., Mylopoulos, J., NonFunctional Requirements in Software Engineering Kluwer Academic Publishers - Massachusetts, USA, 2000.

[9] Fung, A., Graham, M. and Weil, D., "Full disclosure, the perils and promise of transparency", Cambridge University Press, Cambridge, 2007.

[10] Harrison, T.M., Guerrero, S., Burke, G.B., Cook, M.E., Cresswell, A.M., Helbig, N., Hrdinová, J., Pardo, T.A., "Open government and e-government: democratic challenges from a public value perspective", Int. Conf. on Digital Government Research: Digital Government Innovation in Challenging Times, 2011, pp.245-253

[11] Holzner, B., Holzner, L., "Transparency in global change: the vanguard of the open society", University of Pittsburgh Press, Pittsburgh, 2006.

[12] Hosseini, M., Shahri, A., Phalp, K., Ali, R., "Towards engineering transparency as a requirement in sociotechnical systems," Req. Eng. Conference (RE), IEEE 23rd International, Ottawa, ON, 2015, pp. 268-273.

[13] Kiczales, G., Lamping, J., Mendhekar, A., Maeda, C., Lopes, C., Loingtier, J., Irwin, J., "Aspect-oriented programming", in Proc. of the 11th European Conference on Object-Oriented Programming, Springer-Verlag, 1997.

[14] Leite, J.C.S.P., Cappelli, C., "Software Transparency", Business and Information Systems Engineering, v.2, i.3, 2010, pp.127-139.

[15] Lord K. M., "The Perils and Promise of Global Transparency”, State University of New York Press, 2006.

[16] Pinheiro, A., Cappelli C., Maciel C., "Increasing Information Auditability for Social Network Users", Human Interface and the Management of Information, Information and Knowledge Design and Evaluation. Springer International Publishing, 2014, pp. 536-547.

[17] Serrano, M., Leite, J. P. S., "Capturing TransparencyRelated Requirements Patterns through Argumentation", 2011 1st Int. Work. on Req. Patterns, 2011, pp. 32-41

[18] Vitvar, T., Peristeras, V., Tarabanis, K., "Semantic Technologies for E-Government: An Overview", In: Semantic Technologies for E-Government, Springer-Verlag Berlin Heidelberg, 2010, pp. 1-22.

[19] Wahid, F., "Themes of Research on eGovernment in Developing Countries: Current Map and Future Roadmap", Proceedings of the 2013 46th Int. Conf. on Systems Sciences (HICSS), Wailea, HI, USA, 2013, pp.1743-1752.

[20] Wooldridge, M., "An Introduction to MultiAgent Systems", John Wiley \& Sons Ltd., 2nd ed, 2009.

[21] Yu, E., Giorgini, P., Maiden, N., Mylopoulos, J., "Social modeling for requirements engineering: An introduction", Social Mod. for Req. Eng., 2011, pp. 3-10. 